\title{
Stroke after Hospitalization: Assessment of Functional Prognosis through Disability and Dependency in CNHU-HKM, Cotonou, Benin
}

\author{
Dieu Donné Gnonlonfoun ${ }^{1}$, Paul Macaire Ossou-Nguiet ${ }^{2}$, Lansana Laho Diallo ${ }^{3}$, \\ Constant Adjien1, Isaac Avlessi' ${ }^{1}$, Octave Houannou1, Gérald Goudjinou' ${ }^{1}$, \\ Jocelyn Acakpo ${ }^{4}$, Dismand Houinato ${ }^{1}$, Dossou Gilbert Avode ${ }^{1}$ \\ ${ }^{1}$ Neurology Department, Centre National Hospitalier et Universitaire Hubert Koutoukou Maga (CNHU-HKM), \\ Cotonou, Benin \\ ${ }^{2}$ Neurology Department, Centre Hospitalier et Universitaire (CHU), Brazzaville, Congo \\ ${ }^{3}$ Neurology Department, Centre Hospitalier et Universitaire (CHU), Conakry, Guinea \\ ${ }^{4}$ Epidemiology Institute, Faculté des Sciences de la Santé de I'Université d'Abomey Calavi (FSS/UAC), \\ Cotonou, Benin \\ Email: "dignon2002@yahoo.fr
}

Received 10 April 2014; revised 8 May 2014; accepted 5 June 2014

Copyright (C) 2014 by authors and Scientific Research Publishing Inc.

This work is licensed under the Creative Commons Attribution International License (CC BY).

http://creativecommons.org/licenses/by/4.0/

(c) (i) Open Access

\section{Abstract}

Introduction: Stroke results in severe disability, with impacts that are sometimes socially, emotionally or professionally dramatic and also dramatic for the cost involved in care and treatment. Objective: Assessing the functional prognosis after hospitalization and identifying associated factors. Method: It consisted in a cross-sectional, prospective, descriptive and analytical study that was conducted from April 1 to August 31, 2013 in the Neurology Department of CNHU-HKM in Cotonou. It involved 100 patients who have known stroke for at least 6 months and were all admitted and discharged later on. The disease survivors were re-contacted and examined again at home or at hospital. Disability and dependency were then measured respectively with the Rankin score and Barthel index. The STATA/IC11.0 statistical software was used as the basis for data analysis. Unvaried and multi-varied analyzes helped to identify associated factors. Results: The overall disability and dependency rates were respectively $69 \%$ and $57.7 \%$. And the highest rate of disability (38.8\%) was observed between 50 and 60 years old. However, dependency prevalence was higher in subjects above 70 years old (37.3\%). Regarding gender, the prevalence of disability was $59.2 \%$ in men and rather $41.5 \%$ in women. Predictors of disability and dependency were paralysis on admission (IC95\% $=0.26$ [0.77 - 0.92]; $p=0.036)$, obesity (IC95\% $=0.26[0.77-0.92] ; p=0.012$ ) and monthly income lower than 70\$US (IC95\% $=0.05[0.01-0.56] ; p=0.015)$. Conclusion: This study enabled

${ }^{*}$ Corresponding author.

How to cite this paper: Gnonlonfoun, D.D., et al. (2014) Stroke after Hospitalization: Assessment of Functional Prognosis through Disability and Dependency in CNHU-HKM, Cotonou, Benin. Neuroscience \& Medicine, 5, 139-148.

http://dx.doi.org/10.4236/nm.2014.53017 
us to assess the functional outcome of patients once discharged. The significance of motor deficit on stroke occurrence, obesity and the low monthly income were factors of poor functional prognosis.

\section{Keywords}

Prognosis, Functional, Stroke, Rankin, Barthel, Cotonou, Benin

\section{Introduction}

Stroke causes severe disability, with impacts that are sometimes socially, emotionally or professionally dramatic and also dramatic for the cost of care involved in care and treatment [1] [2]. The lost of independency with regard to hemiplegic patients is significant since $50 \%$ to $70 \%$ of stroke patients depending on a third party [3]-[5]. The current state is not well-known in Benin. That's why this study was initiated and referred out to assess post hospitalization functional prognosis as well as to identify associated factors.

\section{Method}

This is a cross-sectional, prospective descriptive and analytical study conducted from April 1, 2013 to August 31, 2013 in Hubert Maga Koutoukou National teaching hospital in Cotonou. Benin is a French-speaking country in West Africa (Figure 1) bordered in the east by Nigeria. It boasts of 9 million inhabitants covering an area of $112.622 \mathrm{~km}^{2}$. The population subject to study consisted of patients suffering from stroke at least for the past 6 months. The sample size was calculated using the formula of Daniel Schwartz $\mathrm{n}=\mathrm{Z} \alpha^{2} \mathrm{pq} / \mathrm{i}^{2}=96$ with $\mathrm{p}=48.3 \%$ (stroke prevalence in the neurology department in CNHU-HKM [6], $\alpha=5 \%$ and I $=10 \%$. The total number of enrolled subjects during the study period was 100. During the study period, we performed a systematic enrollment of all patients who met the inclusion criteria and willingly agreed to participate in the study, up to the number expected.

\subsection{Inclusion Criteria}

- Having suffered from stroke and been treated in the Department of Neurology;

- Having been suffering from stroke for at least 6 months;

- Having provided one's contacts in the medical record during hospitalization.

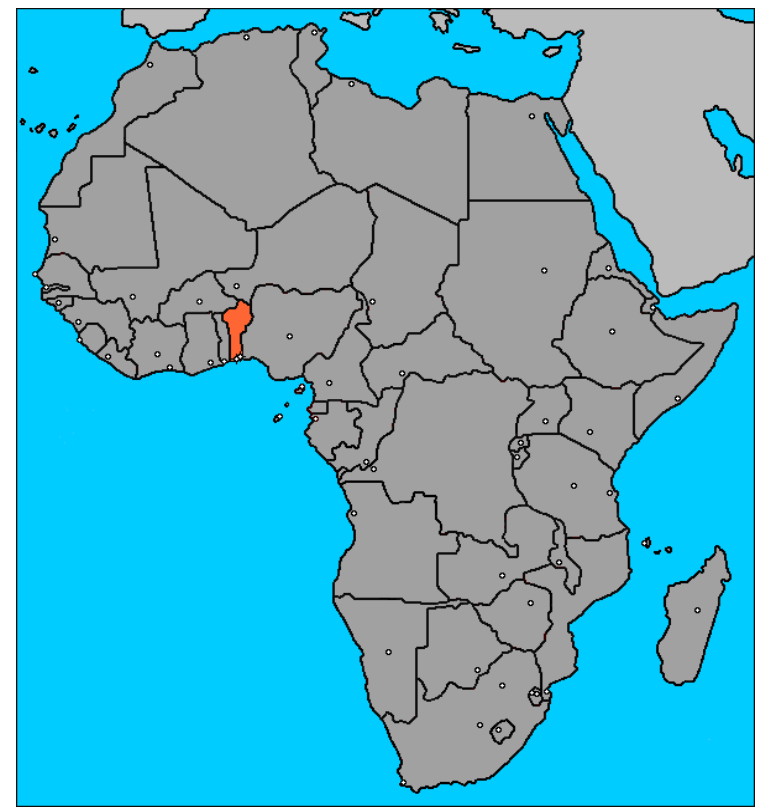

Figure 1. Position of Benin in Africa. 


\subsection{Exclusion Criteria}

- Any patient with a meningeal hemorrhage, cerebral venous thrombosis or a neurological deficit associated with head injury or brain tumor or other cause;

- Exception of brain scan.

\subsection{Diagnostic Criteria}

In this study, stroke diagnosis is made on the basis of a neurological deficit of sudden acute onset and the outcome of brain scan.

\subsection{Collection Modalities}

From the patient folder and database made available by the service, all patients having suffered from stroke and meeting the inclusion criteria were identified up to the sample size. Only those who survived stroke and were discharged after hospitalization were contacted via phone. Those who were still alive were re-examined either at hospital or in their home on appointment basis. A clinical examination of the patient was then carried out through a set of questionnaire. The data were supplemented by the analysis of patient medical records.

\subsection{Studied Variables}

Dependent variables: they include

- The functional disability formerly assessed by the Rankin score. As a matter of fact, a Rankin of 0 or 1 was regarded as absence of disability, and above 1 as presence of disability.

- The dependency state assessed using Barthel index. The patient was considered as dependent when his Barthel index was below 100.

Independent variables:

- The socio-demographic data (age, gender, occupation, marital status, monthly income. The legal minimum wage in Benin is US \$70).

- Past records (hypertension, diabetes, heart disease).

- Data on stroke occurrence: date of stroke occurrence, stroke type, hemicorpus deficit, hypertension, type of deficit, aphasia, impaired consciousness, length of time between stroke and investigation day, use of traditional medicine after hospitalization, functional rehabilitation sessions.

- The current body mass index which helped identify normal subjects $(18<\mathrm{BMI}<25)$, those with overweight $(25<$ BMI < 30) and obesity (BMI > 30).

\subsection{Data Processing and Analysis}

Data were entered using EPI-DATA software. Then, clearance and data analysis were performed using the statistical software STATA/IC 11.0. A descriptive analysis was completed with regard to the variables which were studied. Thus, considering qualitative variables, prevalence rate and proportions were determined. Either chi2 or FISHER test was utilized for comparisons if only expected values are lower than 5 . For the quantitative values, averages along with their typical gaps, medians, minima and maxima have all been described. STUDENT test was utilized for comparisons. The study of associated factors was conducted using logistical regression model in unvaried and multi-varied analyses. The multi-varied analysis was carried out by inserting into the model all variables of which p-value in unvaried analysis is less or equal to $20 \%$ due to the exploratory nature of the study. The break-even point in terms of significance was $5 \%$ and confidence gap rated at $95 \%$.

\subsection{Ethical Considerations}

Each patient or his/her next of kin submitted a written letter of consent upon explanation of the objective and modalities of such a study.

\section{Results}

In total, 100 patients were enrolled. Their ages ranged from 18 - 86 years with an average of 58.9 years \pm 13.6 years. There were $58 \%$ of men against $42 \%$ of women with a sex ratio $(\mathrm{M} / \mathrm{F})$ of 1.4 . Twenty-nine patients 
passed away, which represents a post hospitalization mortality rate of $40.8 \%$. The overall disability prevalence rate among the 71 survivors was $69 \%$. Prevalence according to the Rankin score showed that $15.5 \%$ of patients presented mild disability, $26.7 \%$ presented moderate disability, $16.9 \%$ presented moderately severe disability and $9.9 \%$ presented severe disability (Figure 2). Dependency prevalence was $57.7 \%$.

Socio-demographically, the highest disability rate (38.8\%) was observed between 50 and 60 years old. However, dependency prevalence was higher in subjects over 70 years $(37.3 \%), p=0.320$. These data are summarized in Figure 3. Concerning gender, disability prevalence was $59.2 \%$ in men population whilst the rate was 41.5\% in women population as shown in Figure 4. Figure 5 on the other hand shows the progress of both disability and dependency over time in stroke patients' population.

Clinically, disability prevalence was $65.3 \%$ when the patient showed paralysis on stroke occurrence. Under the same conditions, dependency was 76.9\% (Figure 6). Disability rate is higher in patients with hemorrhagic stroke $(79.2 \%, \mathrm{p}=0.003)$, whilst dependency ratio is higher in patients with ischemic stroke $(59.6 \%, \mathrm{p}=0.03)$. Figure 7 summarizes these data.

As far as therapy is concerned, a gradual decline in disability and dependency is observed based on functional rehabilitation sessions (Figure 8).

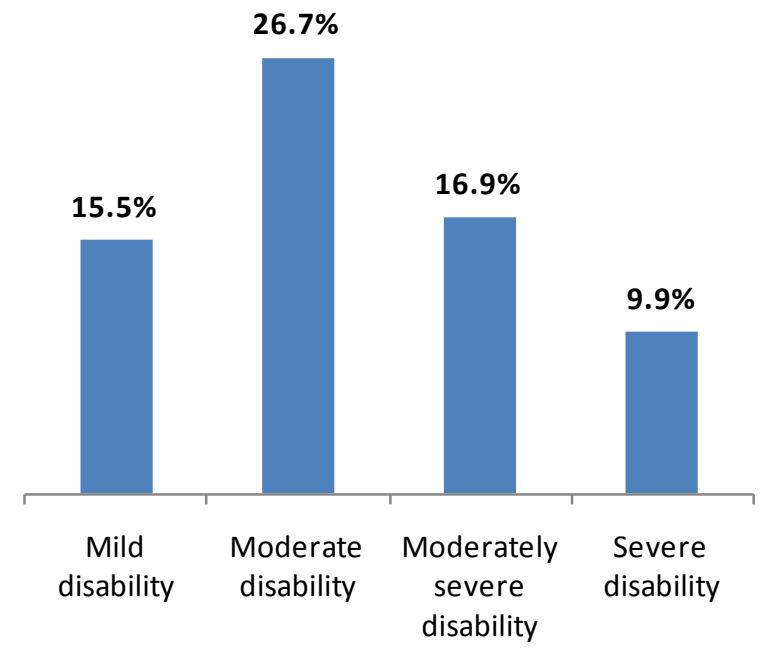

Figure 2. Prevalence of different types of disability, Cotonou, 2013.

$38.8 \%$

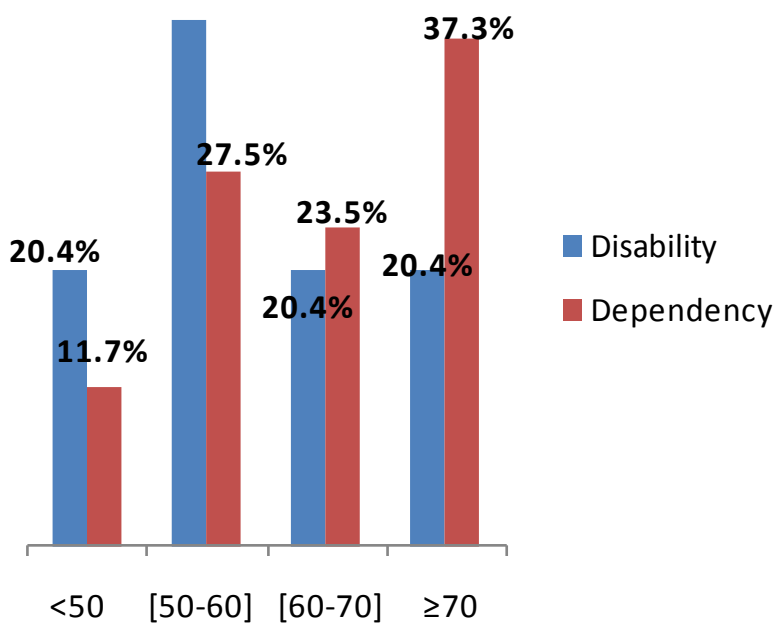

Figure 3. Distribution of disability prevalence per age, Cotonou, 2013. 


\section{$59.2 \%$}
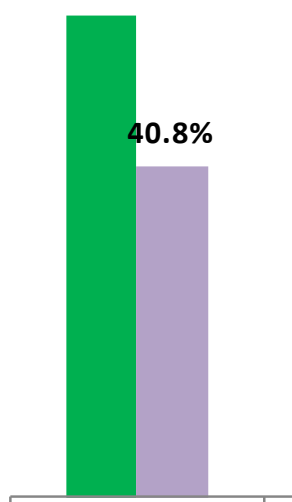

Disability
$58.5 \%$

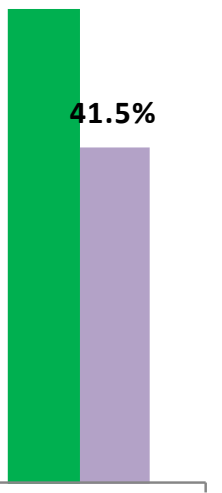

Male

Female

Figure 4. Disability and dependency prevalence as per gender, Cotonou, 2013.

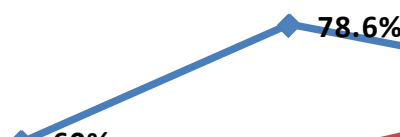

$60 \%$
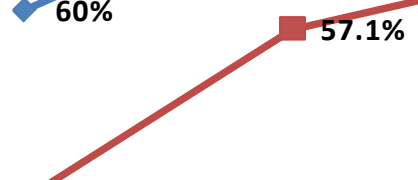

$30 \%$

\section{$70.4 \%$}

$66.7 \%$
$66.7 \%$

33.3\% Disability
- Dependency

$<1$ year

[1-2 years]

[2-3 years]

$>3$ year

Figure 5. Disability and dependency distribution per time spent after stroke occurrence, Cotonou, 2013.

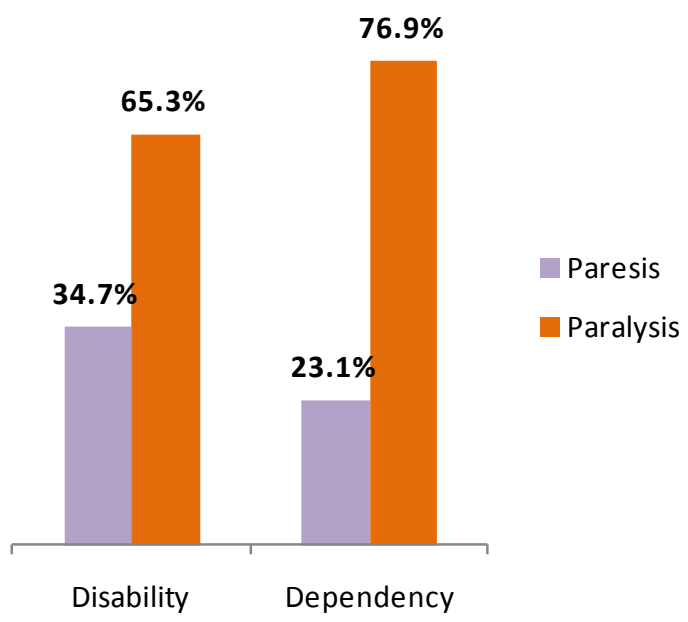

Figure 6. Distribution of disability and dependency prevalence per type of deficit on stroke occurrence, Cotonou, 2013. 


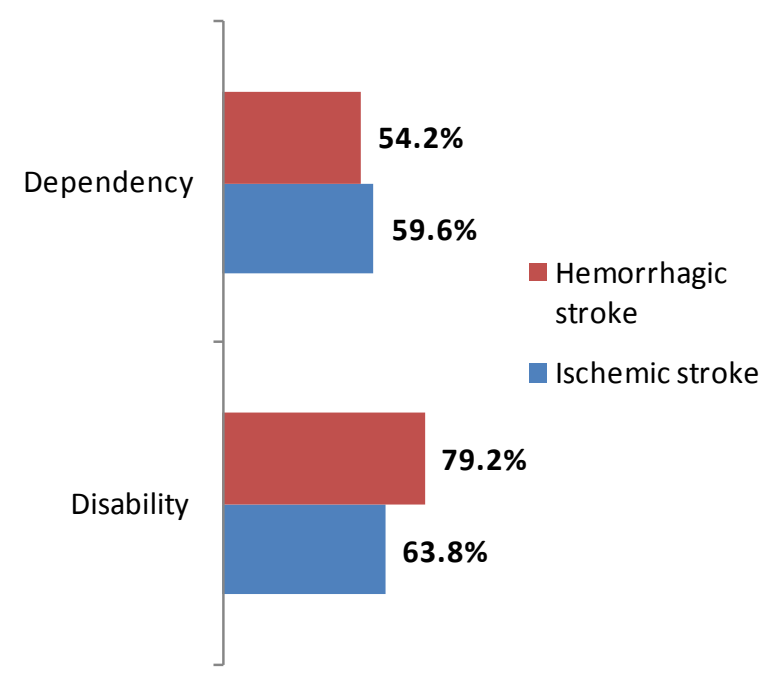

Figure 7. Disability and dependency distribution per stroke type, Cotonou, 2013.
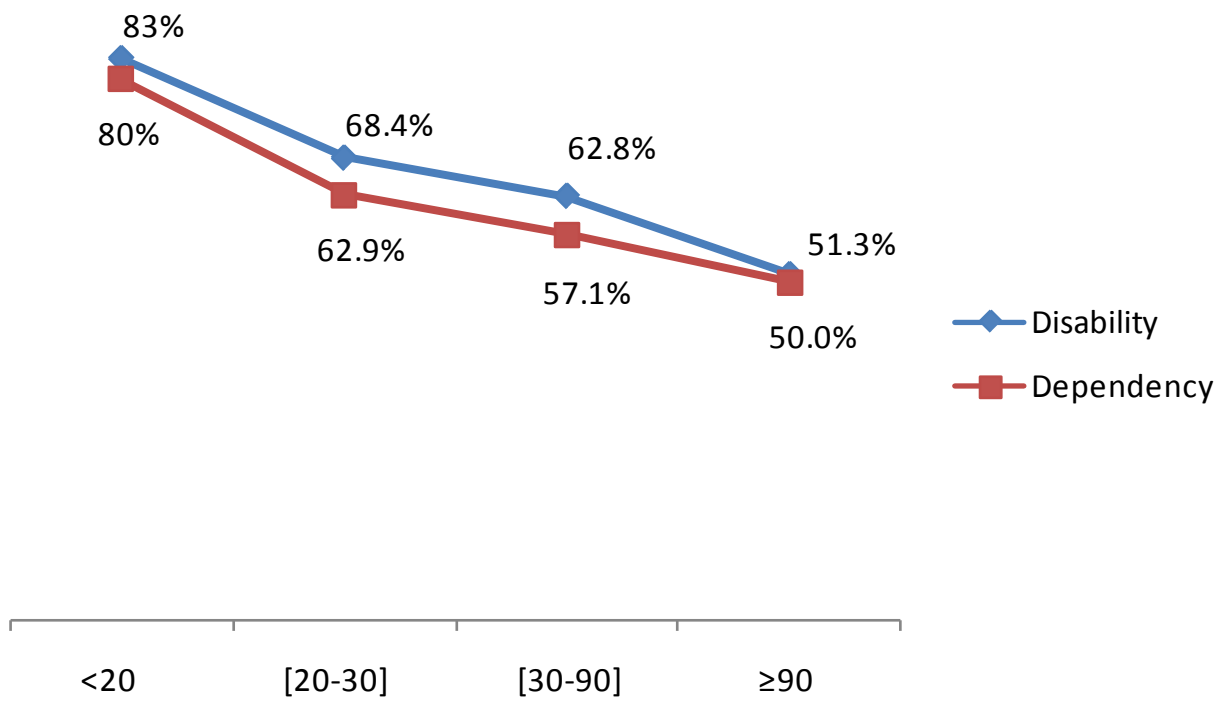

Figure 8. Disability and dependency distribution per number of physiotherapy session, Cotonou, 2013.

Associated factors: the unvaried analysis shows that no socio-demographic data is significantly associated with disability. On the other hand, age between 60 and 70 (95\% IC $=12$ [2.01 to 71.81], p = 0.034), age above 70 (95\% IC = 6 [1.17 to 30.72]; $\mathrm{p}=0.013$ ) and monthly income lower than $\$ 70$ (95\% IC $=0.21$ [0.57 to 0.82], $\mathrm{p}=$ 0.012) were associated with dependency (Table 1). In terms of medical past records, only the presence of hypertension was associated with disability (95\% IC $=7.15$ [1.64 to 31.20], $\mathrm{p}=0.004)$ and dependency (95\% IC = 17.14 [2.03 to 144.6], $\mathrm{p}=0.001$ ) as indicated in Table 2. Clinically, the presence of paralysis on patient admission during stroke occurrence ( $95 \%$ IC $=0.21$ [0.06 - 0.64], $\mathrm{p}=0.005$ ), the presence of hypertension on admission (95\% IC $=13.82$ [1.50 to 126.9 ], $\mathrm{p}=0.004$ ) and obesity ( $95 \%$ IC $=0.18$ [0.59 to 0.65], $\mathrm{p}=0.017$ ) were associated with disability. These same factors were associated with dependency: paralysis on admission (95\% IC = 0.14 [0.05 to 0.41 ], $\mathrm{p}<0.001$ ), hypertension on admission ( $95 \% \mathrm{IC}=8.33$ [2.92 to 75.65], $\mathrm{p}=0.029$ ), and obesity (95\% IC $=7.17$ [0.84 to 61.27], $\mathrm{p}=0.042$ ). These data are summarized in Table 3.

Disability and dependency predictors: After multi-varied analysis with logistical regression, paralysis on admission (95\% IC $=0.26$ [0.77 to 0.92], $\mathrm{p}=0.036)$ and obesity (95\% IC $=0.26$ [0.77 to 0.92], $\mathrm{p}=0.012$ ) were factors that remained associated with disability. As for dependency, only paralysis on admission (95\% IC $=0.27$ 
D. D. Gnonlonfoun et al.

Table 1. Socio-demographical factors associated with disability and independency, Cotonou, 2013. Results of unvaried analysis.

\begin{tabular}{|c|c|c|c|c|c|c|c|}
\hline & Total & $\begin{array}{c}\text { Disability } \\
\text { n (\%) }\end{array}$ & RC $\left[I_{95 \%}\right]$ & $\begin{array}{c}\mathbf{p} \\
\text { Value }\end{array}$ & $\begin{array}{c}\text { Dependency } \\
\text { n (\%) }\end{array}$ & RC $\left[I_{95 \%}\right]$ & p Value \\
\hline Age (years) & & & & 0.434 & & & \\
\hline$<50$ & 18 & $10(55.6)$ & 1 & & $6(33.3)$ & 1 & \\
\hline [50 - 60] & 27 & $19(70.4)$ & $1.9[0.55-6.59]$ & & 14 (51.9) & $2.15[0.62-7.42]$ & \\
\hline$[60-70]$ & 14 & $10(71.4)$ & $2[0.45-8.84]$ & & 12 (85.7) & $12[2.01-71.81]$ & $0.034^{*}$ \\
\hline$>70$ & 12 & $10(83.3)$ & $4[0.67-23.7]$ & & $9(75.0)$ & $6[1.17-30.72]$ & $0.013^{*}$ \\
\hline Gender & & & & 0.470 & & & 0.486 \\
\hline Male & 44 & 29 (65.9) & 1 & & $24(54.5)$ & 1 & \\
\hline Female & 27 & $20(74.1)$ & $1.48[0.51-4.2]$ & & 17 (62.9) & $1.42[0.53-3.78]$ & \\
\hline $\begin{array}{l}\text { Matrimonial } \\
\text { status }\end{array}$ & & & & 0.161 & & & 0.553 \\
\hline Single & 21 & $12(57.1)$ & 1 & & $11(52.4)$ & 1 & \\
\hline Married & 50 & $37(74.0)$ & $2.13[0.73-6.2]$ & & $30(60.0)$ & $1.36[0.49-3.81]$ & \\
\hline Profession & & & & 0.606 & & & 0.210 \\
\hline Civil servant & 22 & 17 (77.3) & 1 & & $15(68.2)$ & 1 & \\
\hline Private worker & 10 & $6(60.0)$ & $0.44[0.09-2.2]$ & & $3(30.0)$ & $0.2[0.39-1.01]$ & \\
\hline Craftsman & 11 & $8(72.7)$ & $0.78[0.15-4.1]$ & & $5(45.4)$ & $0.39[0.09-1.72]$ & \\
\hline Housewife & 19 & 14 (73.7) & $0.82[0.19-3.4]$ & & $12(63.2)$ & $0.8[0.22-2.92]$ & \\
\hline Monthly income & & & & 0.204 & & & $0.012^{*}$ \\
\hline$<70 \$$ & 11 & $7(63.6)$ & $2.7[0.75-9.2]$ & & $9(81.8)$ & $2.66[0.50-14.2]$ & \\
\hline$[70 \$-200 \$]$ & 35 & $22(62.9)$ & $0.9[0.59-0.72]$ & & 22 (62.9) & $0.21[0.57-0.82]$ & \\
\hline$>200 \$$ & 15 & $4(26.7)$ & 1 & & $4(26.7)$ & 1 & \\
\hline
\end{tabular}

${ }^{*}$ Significant result.

Table 2. Past records associated with disability and dependency, Cotonou, 2013. Results of unvaried analysis.

\begin{tabular}{|c|c|c|c|c|c|c|c|}
\hline Past records & Total & $\begin{array}{l}\text { Disability } \\
\text { n (\%) }\end{array}$ & RC [IC $\left.{ }_{95 \%}\right]$ & p Value & $\begin{array}{c}\text { Dependency } \\
\text { n (\%) }\end{array}$ & RC $\left[\right.$ IC $\left._{95 \%}\right]$ & p Value \\
\hline Hypertension & & & & $0.004^{*}$ & & & $0.001^{*}$ \\
\hline No & 10 & $3(30.0)$ & 1 & & $1(10.0)$ & 1 & \\
\hline Yes & 61 & $46(75.4)$ & 7.15 [1.64 - 31.20] & & $40(65.6)$ & $17.14[2.03-144.6]$ & \\
\hline Diabetes & & & & 0.698 & & & 0.294 \\
\hline No & 63 & $43(68.2)$ & 1 & & $35(55.6)$ & 1 & \\
\hline Yes & 8 & $6(75.0)$ & $1.39[0.26-7.53]$ & & $6(75.0)$ & $2.4[0.44-12.8]$ & \\
\hline Heart disease & & & & 0.651 & & & 0.916 \\
\hline No & 66 & 46 (69.7) & 1 & & 38 (57.6) & 1 & \\
\hline Yes & 5 & $3(60.0)$ & $0.65[0.10-4.21]$ & & $3(60.0)$ & $1.11[0.17-7.06]$ & \\
\hline
\end{tabular}

*Significant result.

[0.01 to 0.28], $\mathrm{p}=0.003$ ) and monthly income under $\$ 70$ (95\% IC $=0.05$ [0.01 to 0.56], $\mathrm{p}=0.015)$ were closely associated as shown in Table 4.

\section{Discussion}

Disability prevalence in correlation with stroke patients was 69\%. The distribution per Rankin score showed that $15.5 \%$ of patients presented mild disability, $26.7 \%$ presented moderate disability, $16.9 \%$ presented moderately severe disability and 9.9\% presented severe disability. Layadi et al. [5], in a study conducted in Algeria in 2008 
Table 3. Clinical factors associated with disability and dependency, Cotonou, 2013. Results of unvaried analysis.

\begin{tabular}{|c|c|c|c|c|c|c|c|}
\hline Factors & Total & $\begin{array}{c}\text { Disability } \\
\text { n (\%) }\end{array}$ & RC $\left[\mathrm{IC}_{95 \%}\right]$ & p Value & $\begin{array}{c}\text { Dependency } \\
\text { n (\%) }\end{array}$ & RC $\left[\right.$ IC $\left._{95 \%}\right]$ & p Value \\
\hline Deficit side & & & & 0.291 & & & 0.447 \\
\hline Right & 47 & $31(65.9)$ & 1 & & $29(61.7)$ & 1 & \\
\hline Left & 23 & $18(78.3)$ & $1.86[0.58-5.93]$ & & $12(52.2)$ & $0.68[0.25-1.85]$ & \\
\hline Deficit importance & & & & $0.005^{*}$ & & & $<0.001^{*}$ \\
\hline Paresis & 38 & $32(84.2)$ & 1 & & 30 (78.9) & 1 & \\
\hline Paralysis & 32 & $17(53.1)$ & $0.21[0.06-0.64]$ & & $11(34.4)$ & $0.14[0.05-0.41]$ & \\
\hline Impaired consciousness & & & & 0.892 & & & 0.83 \\
\hline No & 46 & $32(69.6)$ & 1 & & 27 (58.7) & 1 & \\
\hline Yes & 25 & $17(68.0)$ & $0.93[0.33-2.65]$ & & $14(56.0)$ & $0.89[0.33-2.39]$ & \\
\hline A. Hypertension & & & & $0.004^{*}$ & & & $0.029^{*}$ \\
\hline No & 6 & $1(16.7)$ & 1 & & $1(16.7)$ & 1 & \\
\hline Yes & 64 & 47 (73.4) & 13.82 [1.50 - 126.9] & & $40(62.5)$ & $8.33[2.92-75.65]$ & \\
\hline Aphasia & & & & 0.637 & & & 0.817 \\
\hline No & 32 & 23 (71.9) & 1 & & $18(56.2)$ & 1 & \\
\hline Yes & 39 & $26(66.7)$ & $0.78[0.28-2.17]$ & & $23(58.9)$ & $1.12[0.43-2.88]$ & \\
\hline Traditional M. & & & & 0.379 & & & 0.115 \\
\hline No & 43 & $28(65.1)$ & 1 & & 35 (54.7) & 1 & \\
\hline Yes & 28 & $21(75.0)$ & $1.61[0.56-4.64]$ & & $6(85.7)$ & $4.97[0.56-43.69]$ & \\
\hline BMI & & & & $0.017^{*}$ & & & $0.042^{*}$ \\
\hline Normal & 34 & $15(44.1)$ & 1 & & $15(44.1)$ & 1 & \\
\hline Overweight & 16 & $8(50.0)$ & $0.23[0.37-1.44]$ & & $8(50.0)$ & $0.78[0.28-2.17]$ & \\
\hline Obese & 12 & $10(83.3)$ & $0.18[0.59-0.65]$ & & $10(83.3)$ & $7.17[0.84-61.27]$ & \\
\hline
\end{tabular}

*Significant result.

Table 4. Predictors of disability due to stroke, Cotonou, 2013. Results of multi-varied analysis.

\begin{tabular}{ccccccccc} 
& $\begin{array}{c}\text { Disability } \\
\mathbf{n}(\%)\end{array}$ & Gross RC & Adjusted RC & p Value & $\begin{array}{c}\text { Dependency } \\
\mathbf{n}(\%)\end{array}$ & Gross RC & Adjusted RC & p Value \\
\hline Paralysis & $32(53.1)$ & $0.21[0.06-0.64]$ & $0.26[0.77-0.92]$ & $0.036^{*}$ & $12(52.2)$ & $0.68[0.25-1.85]$ & $0.27[0.01-0.28]$ & $0.003^{*}$ \\
Obesity & $15(44.1)$ & $0.18[0.59-0.65]$ & $0.19[0.05-0.69]$ & $0.012^{*}$ & - & - & - & - \\
RM $<70 \$$ & - & - & - & - & $4(26.7)$ & $0.21[0.57-0.82]$ & $0.05[0.01-0.56]$ & $0.015^{*}$ \\
\hline
\end{tabular}

*Significant results.

on the assessment of functional prognosis in stroke hemiplegics in 2007, recorded a disability prevalence of $67 \%$. This result is similar to ours, and shows how high the level of disability is after stroke occurrence.

Dependency prevalence was $57.7 \%$ in this study. It included all patients who had a Barthel index lower than 100. Some studies had similar results. Wilkinson et al. [3] in 1997 in a study on the long-term monitoring of stroke and Le Thiec et al. [4] in a study on stroke mortality and functional outcome in Lower Normandy in France, realized that the lost of independency with regard to hemiplegia patients was significant since 50\% - 70\% of them depended on a third party.

Age impact on functional outcome is appreciated in many different ways [7] [8]. In our study, age seemed to influence the progression of Barthel score when the subject is beyond 70 years, although the difference was not statistically significant $(\mathrm{p}=0.320)$. With respect to disability, it was more prevalent in patients' population between 50 and 60 years with a minor difference. In our research, the non-correlation between age, disability and dependence might be explained by the smaller sample size culminating in the shortfalls. We could have observed significance thresholds if sample size was more important. In a prospective study assessing 561 patients, 
age was a predictor of neither the progression of FIM nor final FIM [9]. Davier, in a follow-up research conducted on 156 victims of a first hemispheric stroke consecutively admitted for a year to the Teaching Hospital of Limoges in France, does not accept age as a predictor of stroke functional outcome [10]. For Calmels, old age significantly reduces the final level of functional independency as well as the prevalence of returning home [11].

Sixty percent (60\%) of patients who had stroke less than a year ago presented a disability; that prevalence decreased to $33.3 \%$ for patients seen 3 years after stroke event. This shows that disability prevalence reduces over time. Natural progress and rehabilitation sessions might influence such recovery [12]. Beyond the third year, dependence did not know a significant decline. The fact that disability decreases whilst dependence does not follow the same trend, might be due to the psychological advantages of dependence. In fact, dependent patients have support from their relatives to carry out daily activities and find it difficult to do without, despite their disability decline.

For Ischemic stroke, $42.9 \%$ of patients had a disability within less than a year against $28.6 \%$ beyond 3 years. For hemorrhagic stroke, $75 \%$ of patients had a disability within less than a year with a considerable decrease in this rate over time. It became apparent that, hemorrhagic stroke allowed a functional recovery higher than that of ischemic stroke. Several studies corroborate our results. SENE DIOUF et al. [13] in 2006 in Senegal and PAOLUCI et al. [14] in a comparative study in 2003 made the same observation. Several reasons were given by the work of QURESHI et al. [15] to explain the best prognosis of hemorrhagic lesions. Indeed hemorrhagic lesions compromise less severely the central neuroplasticity mechanisms causing recovery. Moreover, the basic process of hemorrhage, with blood extravasation resulting in the compression and laceration of the cerebral parenchyma, differs from that of ischemia with blood flow interruption leading to hypoxia and a decrease in metabolites that are essential to the survival of brain parenchyma.

In unvaried analysis, several factors were associated with the functional profile. But only the size of deficit during stroke period $(\mathrm{p}=0.036)$, BMI $(\mathrm{p}=0.015)$ and the monthly income $(\mathrm{p}=0.015)$ were found as disability and dependency predictors after multi-varied analysis.

- The importance of motor deficit on stroke occurrence

Patients with paralysis presented less significant recovery than patients with paresis. The more significant motor deficit is on stroke occurrence, the more significant disability is. SENE DIOUF et al. also noted an association between disability and the significance of initial injury [13]. As a matter of fact, the more significant motor deficit is, the higher the number of affected pyramidal fibers is. This results then in a slower recovery than in paresis cases where the amount of injured pyramidal neurons is lower.

\section{- $B M I$}

Disability was more significant in obese patients than in those with normal weight. Obesity already established as a risk factor for stroke, is also revealed as a factor of poor post stroke functional prognosis. Layadi et al. [5] also found obesity as an aggravating factor of disability. Indeed, obesity causes other comorbidities such as hypertension, diabetes and physical inactivity that negatively burden functional prognosis.

- Monthly income

The low monthly income earned by the patients was predictive of poor functional diagnosis. In our study, patients who had a higher monthly income were less dependent. This could be explained by their access to quality care, their ability to afford rehabilitation sessions and also an environment conducive to mental well-being. A link can be established with the results of LAYADI et al. [5] which recorded an association between educational level and functional recovery when we consider that education level is often related to monthly income.

\section{Conclusion}

This study helped assessing the current state in Benin on the functional outcome of patients once they are discharged. The significances of motor deficit on stroke occurrence, obesity and low monthly income were factors of poor functional prognosis. The identification of these factors will now help to determine timely the potential for recovery from hemiplegia.

\section{References}

[1] Kpadonou, G.T., Houinato, D., Alagnide, E., Adjien, C. and Avode, D.G. (2002) Functional Disability in Stroke Hemiplegic in CNHU, Cotonou-Benin: Measures and Main Factors. Le Bénin Médical, 20, 36-40.

[2] Gnonlonfoun, D., Adoukonou, T., Adjien, C., Nkouei, N., Houinato, D., Avode, D.G., et al. (2013) Factors Associated 
with Stroke Direct Cost in Francophone West Africa, the Case of Benin. World Journal of Neuroscience, 3, $287-292$. http://dx.doi.org/10.4236/wjns.2013.34039

[3] Wilkinson, P.R., Wolfe, C.A., Warburton, F.G., Rudd, A.G., Howard, R.S., Ross-Russel, R.W., et al. (1997) A LongTerm Follow-Up of Stroke Patients. Stroke, 28, 507-512. http://dx.doi.org/10.1161/01.STR.28.3.507

[4] Le Thiec, F., Mane, M., Guincestre, J.Y., Lecoutour, X. and Leroy, F. (1996) Hemiplegic Stroke in Lower-Normandy: Mortality and Functional Outcome. Annales de Réadaptation et de Médecine Physique, 39, 131-142. http://dx.doi.org/10.1016/0168-6054(96)80218-2

[5] Layadi, K., Meziane, M., Remaoune, M., Midoun, N. and Hamonet, C. (2008) Assessment of Functional Prognosis in Hemiplegic Stroke Victims. Journal de Réadaptation Médicale, 28, 97-101.

[6] Houinato, D., Avode, D.G., Adjien, C. and Kindjinou, M. (2005) Stroke Epidemiological Profile in Hospitals in Cotonou. Le Bénin Médical, 29, 54-56.

[7] Hendricks, H.T., van Limbeek, J., Geurts, A.C. and Zwarts, M.J. (2002) Motor Recovery after Stroke: A Systematic Review of the Literature. Archives of Physical Medicine and Rehabilitation, 83, 1629-1637. http://dx.doi.org/10.1053/apmr.2002.35473

[8] Petrilli, S., Duruffle, A., Nicolas, B., Pinel, J.F., Kerdoncuff, V. and Gallien, P. (2002) Hemiplegic Stroke and Returning Home. Annales de Réadaptation et de Médecine Physique, 45, 69-76. http://dx.doi.org/10.1016/S0168-6054(01)00179-9

[9] Bagg, S., Pombo, A.P. and Hopman, W. (2002) Effect of Age on Functional Outcomes after Stroke Rehabilitation. Stroke, 33, 179-185. http://dx.doi.org/10.1161/hs0102.101224

[10] Daviet, J.C., Verdie-Kessler, C., Stuit, A., Popielarz, S., Sinzakaraye, A., Munoz, M., et al. (2006) Early Prediction of Functional Outcome One Year after Initial Unilateral Hemispheric Stroke. Annales de Réadaptation et de Médecine Physique, 49, 49-56. http://dx.doi.org/10.1016/j.annrmp.2005.10.005

[11] Calmels, P., Ebermeyer, E., Bethoux, F., Gonard, C. and Fayolle-Minon, I. (2002) Relation between Care at Home and the Level of Functional Independency after a Stroke. Annales de Réadaptation et de Médecine Physique, 45, 105-113. http://dx.doi.org/10.1016/S0168-6054(02)00185-X

[12] Bejot, Y., Caillier, M., Rouaud, O., Benatru, I., Maugras, C., Osseby, G., et al. (2007) Stroke Epidemiology: Impacts on Treatment Decision. La Presse Médicale, 36, 117-127. http://dx.doi.org/10.1016/j.lpm.2006.11.006

[13] Sène Diouf, F., Basse, A.M., Ndao, A.K. and Ndiaye, M. (2006) Stroke Functional Prognostic in Developing Countries: Sénégal. Annales de Réadaptation et de Médecine Physique, 89, 100-104. http://dx.doi.org/10.1016/j.annrmp.2005.11.006

[14] Paoluci, S., Antonucci, G. and Grassom, G. (2003) Functional Outcome of Ischemic and Hemorragic Stroke Patients after Inpatient Rehabilition. Stroke, 34, 2861-2865. http://dx.doi.org/10.1161/01.STR.0000102902.39759.D3

[15] Qureshi, A.L., Wilson, D.A., Hanley, D.A. and Traystman, R.J. (1999) No Evidence for Ischemic Penumbra in Massive Experimental Intracerebral Hemorrhage. Neurology, 13, 199-203.

\section{List of Abbreviations}

$\begin{array}{ll}\text { Abbreviations } & \text { Full meaning } \\ \text { CNHU-HKM } & \text { Centre National Hospitalier et Universitaire Hubert Koutoukou Maga } \\ \text { BMI } & \text { Body Mass Index } \\ \text { FIM } & \text { Functional Independence Measure }\end{array}$

